\title{
THE INFLUENCE OF MICROHABITAT \\ AND PREY AVAILABILITY ON \\ BURROW ESTABLISHMENT OF YOUNG \\ GEOLYCOSA TURRICOLA (TREAT) \\ AND G. MICANOPY WALLACE
}

(ARANEAE: LYCOSIDAE): A LABORATORY STUDY*

\author{
By G. L. Miller \\ Department of Entomology, \\ Mississippi Entomological Museum, \\ Drawer EM, \\ Mississippi State University \\ Mississippi State, MS 39762
}

\section{INTRODUCTION}

The survival of an animal largely depends on its ability to locate and use a suitable habitat. The suitability of a habitat will depend on such things as prey availability, microhabitat characteristics and the interaction of these,but our understanding of the interaction of these factors and how they effect the animal's choice of habitat is poor (Krebs, 1978).

For spiders, there have been many studies which show the importance of habitat characteristics and prey abundance in the selection of foraging and web sites (e.g., Savory, 1930; Enders, 1977; Riechert, 1976; Riechert and Tracy, 1975). However, most studies deal with adult spiders (some exceptions being the work of Waldorf, 1976; Enders, 1977 and Hallander, 1970) and our understanding of which factors may influence habitat selection in newly dispersing young spiders is limited. These factors are particularly important for burrowing wolf spiders (Geolycosa) since the selected burrow site is generally used throughout the life of the spider (Wallace, 1942). In this paper I test selected hypotheses about the interactions among burrow establishment, prey availability, and several microhabitat characteristics in two species of burrowing wolf spiders. This paper is not concerned with the relationship between the burrow site characteristics and survival of the spiderling, which is best studied in the field (see Reichert, 1976 and Reichert and Tracy, 1975 for

*Manuscript received by the editor January 18, 1984. 
examples of elegant field studies concerning habitat selection and survival).

Geolycosa spp. are obligate burrowers which establish a burrow shortly after leaving the mother (Wallace, 1942; McCrone, 1964; pers. observ.) and, with the exception of short foraging sorties and the reproductive wanderings of mature males, live their entire lives within a burrow (Wallace, 1942; McCrone, 1964; McQueen, 1978; Humphreys, 1975; pers. observ.). Generally, newly-dispersing spiderlings construct burrows in the vicinity of the maternal burrow (McQueen, 1978).

\section{Methods ANd Materials}

Specimens-I collected Geolycosa micanopy from Alachua, Levy, Marion and Putnam counties Florida during December 1982 and March 1983 and G. turricola from Oktibbeha County, Mississippi in March 1983. The spiders were housed at room temperature $\left(21^{\circ} \mathrm{C}\right)$ and lighting (ca. 10:14 light:dark) in individual translucent plastic cups containing sand. Most of the spiders constructed burrows in the cups. The spider's diet consisted of crickets, wingless flies and tobacco budworm larvae (Heliothis sp.); and free water was provided.

Several spiders had mated before collection and constructed egg cases in the lab. Most females held the egg case until the young emerged and then tolerated them on her back until they dispersed. However, two G. micanopy and one G. turricola cast the cases from the burrows. The young from these cases were used in the experiments because their feeding experience could be closely controlled. Abandoned cases were kept in individual petri dishes. After about two weeks, I made a small opening in the egg sac and the young emerged. The number of young used for the study was 121 and 98 for the two G. micanopy egg cases and 119 for the G. turricola egg case. Spiderlings congregated on a cotton ball placed near the egg case. Each individual was placed into a glass vial within one week of emergence and held without food (water provided via cotton swab) for about two weeks, at which time the experiments began.

Experimental design and hypotheses-Three experiments were designed to test hypotheses concerning independence among dichotomous grouping variables arranged in three three-way 
Table 1. Observed cell frequencies of burrow establishment for Geolycosa turricola and G. micanopy under experimental conditions. $\mathrm{B}=$ burrow established, $\mathrm{NB}=$ no burrow established.

\begin{tabular}{|c|c|c|c|c|c|c|c|c|}
\hline & \multicolumn{4}{|c|}{ G. turricola } & \multicolumn{4}{|c|}{ G. micanopy } \\
\hline & \multicolumn{2}{|c|}{ Fed } & \multicolumn{2}{|c|}{ Unfed } & \multicolumn{2}{|c|}{ Fed } & \multicolumn{2}{|c|}{ Unfed } \\
\hline & B & NB & B & NB & B & NB & B & NB \\
\hline Vegetation & 25 & 4 & 13 & 17 & 23 & 8 & 7 & 24 \\
\hline No Vegetation & 20 & 10 & 9 & 21 & 22 & 7 & 12 & 18 \\
\hline Crevice & -- & -- & -- & -- & 19 & 6 & 20 & 4 \\
\hline No Crevice & -- & -- & -- & -- & 16 & 9 & 13 & 11 \\
\hline
\end{tabular}

contingency tables. The variables were chosen because of their possible importance as factors in burrow construction based on casual and quantitative observations of laboratory and field populations of five species of Geolycosa (G. turricola, G. micanopy, G. patellonigra, G. ornatipes, G. hubbelli and G. escambiensis). The variables were:

(1) Prey/no prey (PREY)-indicating whether food was provided during the experimental period.

(2) Vegetation/no vegetation (VEGETATION) -indicating whether small bits of grass were provided in the experiemental container.

(3) Crevice/no crevice (CREvICE)-indicating whether a depression in the burrowing surface was provided.

(4) Burrow/no burrow (BURROw) - the "dependent" variable, indicating whether a burrow was constructed. Any burrow which was large enough to contain the spider was scored as an established burrow.

For each experiment I tested two hypotheses concerning a threeway contingency table defined by the variables PREY, BURROW and one of the other two variables (Table 2). The experiments and anaylyses were performed for the two species separately for the data pertaining to the variable vegETATION. No formal statistical comparison of the data for the two species was made. Analysis involving the variable CREvICE was carried out on G. micanopy only. The hypotheses were tested by Chi-square goodness-or-fit tests using Goodman's (1970) maximum likelihood estimators to obtain the expected cell frequencies. 
Sand was used as the burrowing medium in all cases. Spiderlings which were to receive food were given newly-hatched crickets at the beginning of the experimental period. A metal probe was used to make small crevices in the sand where necessary. Restricted randomization was used to assign roughly equal numbers of spiderlings to treatment groups (fed, unfed, etc.). Specimens were held in their test containers at normal room temperature and light for a period of $36 \mathrm{~h}$, at which time I observed whether each had established a burrow or not. Previous observations indicated that burrows are usually established within the first $24 \mathrm{~h}$ after dispersal.

\section{RESULTS}

The first set of hypotheses tested the independence of burrowing with the variables VEGETATION and CREVICE respectively within the levels of the variable PREY (Table 2). The hypothesis that BURROWING is independent of VEGETATION within a PREY group (fed or unfed) was rejected for G. turricola but not for G. micanopy (Table 2). Both fed and unfed $G$. turricola showed a higher number of burrowers in the group that was provided with vegetation ( $86 \%$ and $43 \%$ burrowing in the fed and unfed groups respectively). For $G$. micanopy, the number of burrowers is approximately the same for the fed spiders with and without vegetation. A higher percentage of the unfed G. micanopy burrowed when no vegetation was present (23\% and $40 \%$ for the group with and without vegetation respectively). More spiders burrowed in the presence of a crevice than when no crevice was available for both fed and unfed G. micanopy.

The second set of hypotheses tested the independence of BURROWING and PREY given the level of each of the other two variables. In every case, the hypothesis of independence was rejected (Table 2). In nearly every case, the percentage of spiderlings constructing burrows was lower in the unfed group. This is true for each level of the two variables, VEGETATION and CREVICE except for the unfed G. micanopy who were provided a crevice. In that case, more spiderlings constructed burrows than did not.

\section{Discussion}

The results indicate that, of those variables considered, PREY was most strongly associated with the establishment of a burrow. In nearly every case, groups of spiderlings which were given food had a 


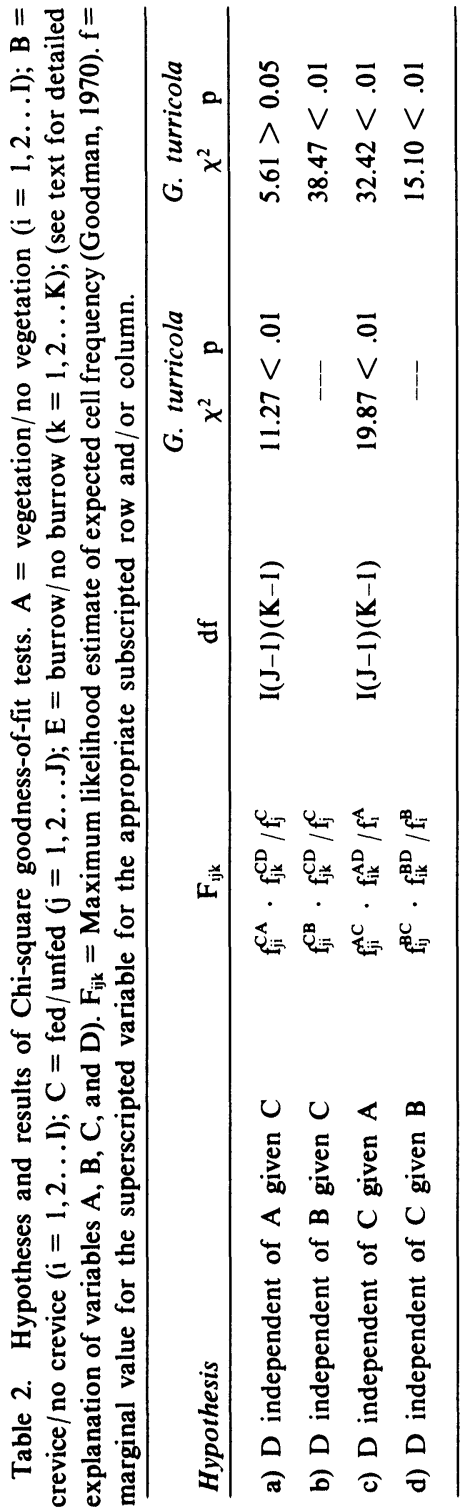


higher percentage of burrows than those that were not. Although the experimental design allows consideration of only the importance of the presence of prey, higher rates of burrow establishment in the presence of food may imply either a nutritional advantage or a response to prey availability.

With respect to nutritional differences, even though burrowing behavior is innate and may be observed as early as in late preemergent spiderlings which have not fed (pers. observ.), the successful establishment of a burrow may be more likely if a spiderling is able to obtain food prior to dispersing. Many lycosid spiderlings disperse after only a short time on the mother (e.g., about seven days, Higashi and Rovner, 1975) and do not feed prior to dispersal (Foelix, 1982). My observations of field populations of other Geolycosa indicate that spiderlings may cling to the mother for up to three weeks and some young remain in the maternal burrow for at least one molt after leaving the mother's abdomen as Engelhardt (1964) found in Trochosa spp. A possible advantage of this extended association with the mother is that those spiderlings that remain may receive nurishment by sharing prey captured by the mother, as in Sosippus floridanus (Brach, 1976), or by cannibalism.

Hallander (1970) observed cannibalism in Pardosa pullata of the same brood, even in situations of high prey density. I held broods of G. turricola and G. patellonigra without food for six weeks and observed few instances of cannibalism. Cannibalism, therefore, is probably not a primary means of obtaining predispersal nourishment in Geolycosa. At present, I do not have information as to whether older juvenile Geolycosa that remain in the burrows are able to obtain food on their own. I have observed spiderlings clinging to the turret rim in a foraging position but $I$ have never observed prey capture.

The means of obtaining predispersal nourishment (if such is obtained) notwithstanding, a lack of food per se does not preclude burrow construction. Significantly more burrows were constructed in the groups which were provided with food but many unfed spiderlings (average $40.8 \%$ ) successfully constructed burrows. Also, observations of lab held and starved G. patellonigra indicated that burrowing may occur well after two weeks post emergence (pers. observ.). 
Riechert and Luczack (1982) recently reviewed the literature concerning the selection of microhabitat in spiders. Environmental factors such as wind (e.g., Eberhard, 1971), vegetation structure (e.g., Enders, 1975) or temperature (e.g., Riechert and Tracy, 1975) and prey characteristics such as prey availability (e.g., Kronk and Riechert, 1979; Enders, 1977; Morse, 1981) are known to influence positioning of webs and the location of foraging sites in spiders. Geolycosa burrows function in both thermoregulation (Humphreys, 1975 ) and prey capture (Gertsch, 1942, pers. observ.), so the placement of the burrow may be related to these functions. However, the major thermoregulatory attribute of the burrow is its depth and not its location relative to the surrounding vegetation (Humphreys, 1975). Geolycosa regulate body temperature by moving up or down the tunnel. The selection of a burrow site, therefore, is more likely to be related to prey availability and microhabitat factors relating to ease of construction or which provide some protection from predators.

The results show a difference between $G$. turricola and $G$. micanopy in the relationship between vegetation availability and frequency of burrow establishment. Within a feeding state, the number of burrows established is independent of vegetation for $G$. micanopy but not for G. turricola. This difference reflects the turret construction habits of the two species. Geolycosa turricola nearly always constructs a conspicuous turret from whatever material is available, whereas G. micanopy shows considerable variation in turret construction and often has burrows with no turret (Wallace, 1942). The different relationship between burrowing frequency and vegetation is probably not a result of a preference for vegetation material used in the experiments, since there appears to be no specificity for turret material in Geolycosa (Wallace, 1942).

Nearly all Geolycosa observed in the lab readily used artificially constructed burrows. Field observations of dispersing G. turricola (Miller and Miller, in prep.) indicate that over one half of burrows constructed by dispersing $G$. turricola spiderlings were built within a surface crack or depression. The results presented here also indicate a preference for burrowing when a surface irregularity is present. Surface cracks and crevices could provide protection from predators and thermoregulatory advantage during the initial phase of 
burrow construction. They may also give the spider a foraging advantage by providing an ambush location. Evidence of the importance of surface cracks is given by the unfed G. micanopy which were provided with cracks. That group constructed nearly as many burrows as the fed group.

\section{SUMMARY}

The relationship between the establishment of a burrow and presence of prey, availability of vegetation and the presence of a crevice in the burrowing surface was investigated in newlydispersing Geolycosa turricola (Treat) and G. micanopy Wallace. The establishment of a burrow by G. turricola was dependent on the presence of vegetation within a feeding group. Establishment of burrows by $G$. micanopy was dependent on the presence of a crevice (not tested for G. turricola). Burrow establishment was found to be dependent on prey availability for any level of the other variables. The dependence on vegetation for burrow establishment in $G$. turricola is attributed to a greater tendency to build turrets in that species. The higher burrowing frequency in the groups that received food during the experiment is thought to be related to nutrition and/or prey availability. The tendency to build new burrows in crevices is known from field studies and may be related to advantages of protection from predators, thermoregulation, or foraging position imparted by the crevice.

\section{ACKNOWLEDGMENTS}

I appreciate the thoughtful comments of J. Rovner, G. Baker, M. LaSalle, R. Altig, M. Morris, P. Ramey-Miller and several anonymous reviewers on various drafts of this paper.

\section{Literature Cited}

Brach, V.

1976. Subsocial behavior in the funnel-web wolf spider Sosippus floridanus (Araneae:Lycosidae). Fla. Ent. 59(3):225-229.

EBERHARD, W. G.

1971. The ecology of the web of Uloborus diversus (Araneae: Uloboridae). Oceologia 6(4):328-342.

ENDERS, F.

1975. The influence of hunting manner on prey size, particularly in spiders with long attack distances (Araneidae, Linyphiidae, and Salticidae). Amer. Natur. 901(970):737-763. 
1977. Web-site selection by orbweb spiders, particularly Argiope aurantia Lucus. Anim. Behav. 15:694-712.

ENGLEHARDT, W.

1964. Die mitteleuropaischen arten der gattung Trochosa C. L. Koch 1848 (Araneae, Lycosidae). Morphologie, chemotaxonomie, biologie, autokologie. Z. Morph. Okol. Tiere 54:219-393.

FoeLIX, R. F.

1982. Biology of Spiders. Harvard University Press. Cambridge, Massachusetts. $306 \mathrm{p}$.

GerTSCH, W. J.

1949. American Spiders. D. van Nostrand Co., Inc. New York. 285 p.

Goodman, L. A.

1970. The multivariate analysis of qualitative data: Interactions among multiple classifications. J. Amer. Stat. Assoc. 65:226-256.

HALlander, $\mathrm{H}$.

1970. Prey, cannibalism and microhabitat selection in the wolf spider Pardosa chelata O. F. Muller and P. pullata Clerck. Oikos 21:337-340.

Humphreys, W. F.

1975. The influence of burrowing and thermoregulatory behavior on the water relations of Geolycosa godeffroyi (Araneae: Lycosidae) an Australian wolf spider. Oecologia 21(4):291-311.

Higashi, G. A. and J. S. Rovner.

1975. Post-emergent behaviour of juvenile lycosid spiders. Bull. Brit. Arch. Soc. 3(5):113-119.

KREBS, C. J.

1978. Ecology: The experimental analysis of distribution and abundance, second edition. Harper and Row, Publishers. New York. 678 p.

Kronk, A. W. and S. E. RIEChert.

1979. Parameters affecting the habitat choice of Lycosa santrita Chamberlin and Ivie. J. Arachnol. 7:155-166.

MCCrone, J. D.

1965. Geographical variation in the seasonal distribution of Geolycosa patellonigra (Araneae, Lycosidae). Am. Mid. Nat. 73(1):166-169.

MCQueEN, D. J.

1978. Field studies of growth, reproduction, and mortality in the burrowing wolf spider Geolycosa domifex (Hancock). Can. J. Zool. 56:2037-2049.

MORSE, D. H.

1981. Prey capture by the crab spider Misumena vatia (Clerck) (Thomisidae) on three common native flowers. Amer. Midl. Natur. 105(2):358-367.

RIECHERT, S. E.

1976. Web-site selection in a desert spider Agelenopsis aperta (Gertsch). Oikos 27:311-315.

Riechert, S. E. AND C. R. TRaCy.

1975. Thermal balance and prey availability: bases for a model relating website characteristics to spider reproductive success. Ecology 56:265-284.

Riechert, S. E. AND J. LuCZaK.

1982. Spider foraging: Behavioral responses to prey. in P. N. Witt and J. S. 
Rovner. eds., Spider Communication: Mechanisms and Ecological Significance. Princeton University Press. Princeton, New Jersey. 236 pp.

SAVORY, T. H.

1930. Environmental differences of spiders of the genus Zilla. J. Ecol., 18:384-385.

WALDORF, E. S.

1976. Spider size, microhabitat selection, and use of food. Am. Mid. Nat. 96(1):76-87.

Wallace, H. K.

1942. A revision of the burrowing spider of the genus Geolycosa (Araneae; Lycosidae). Am. Mid. Nat. 27(1):1-61. 

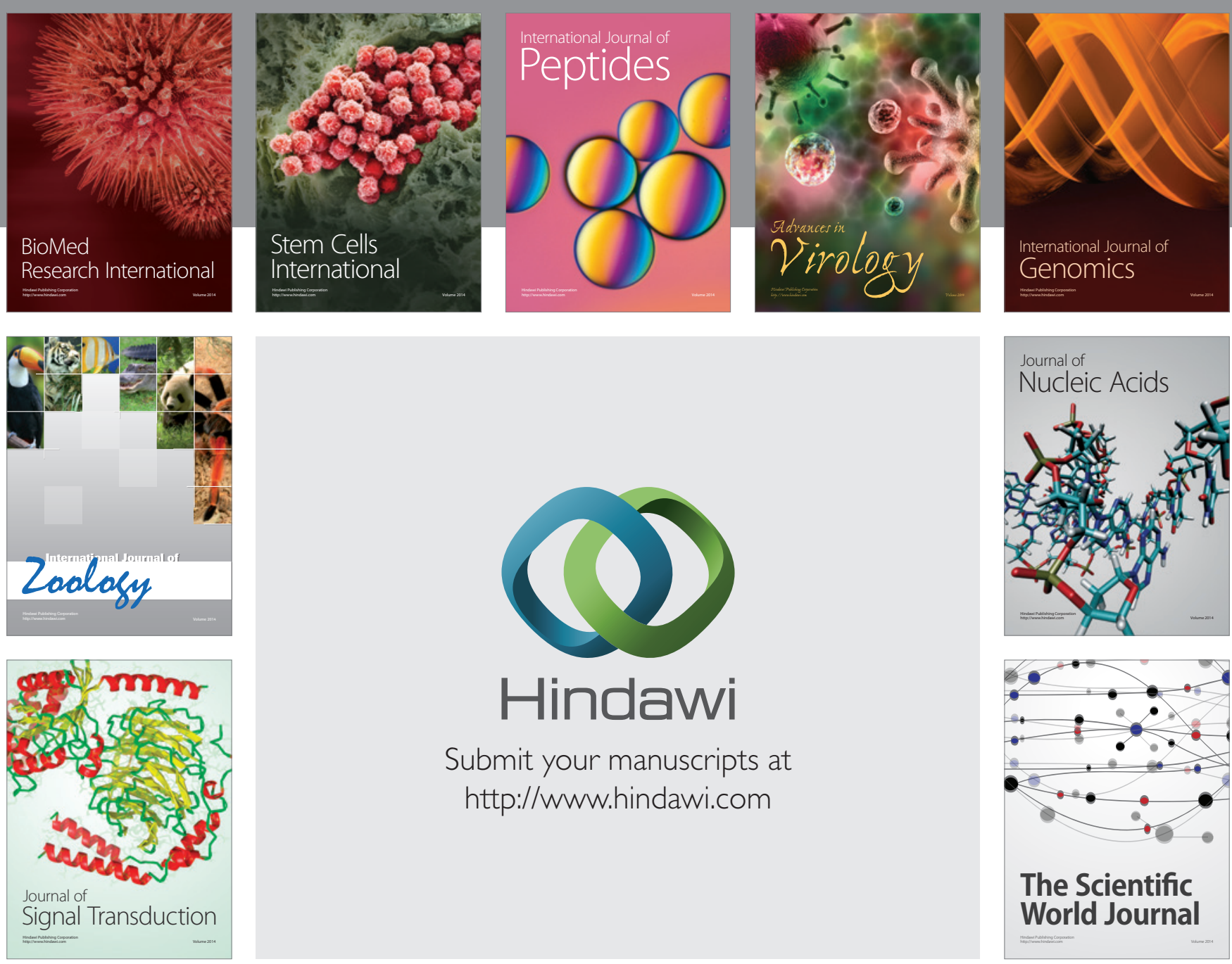

Submit your manuscripts at

http://www.hindawi.com
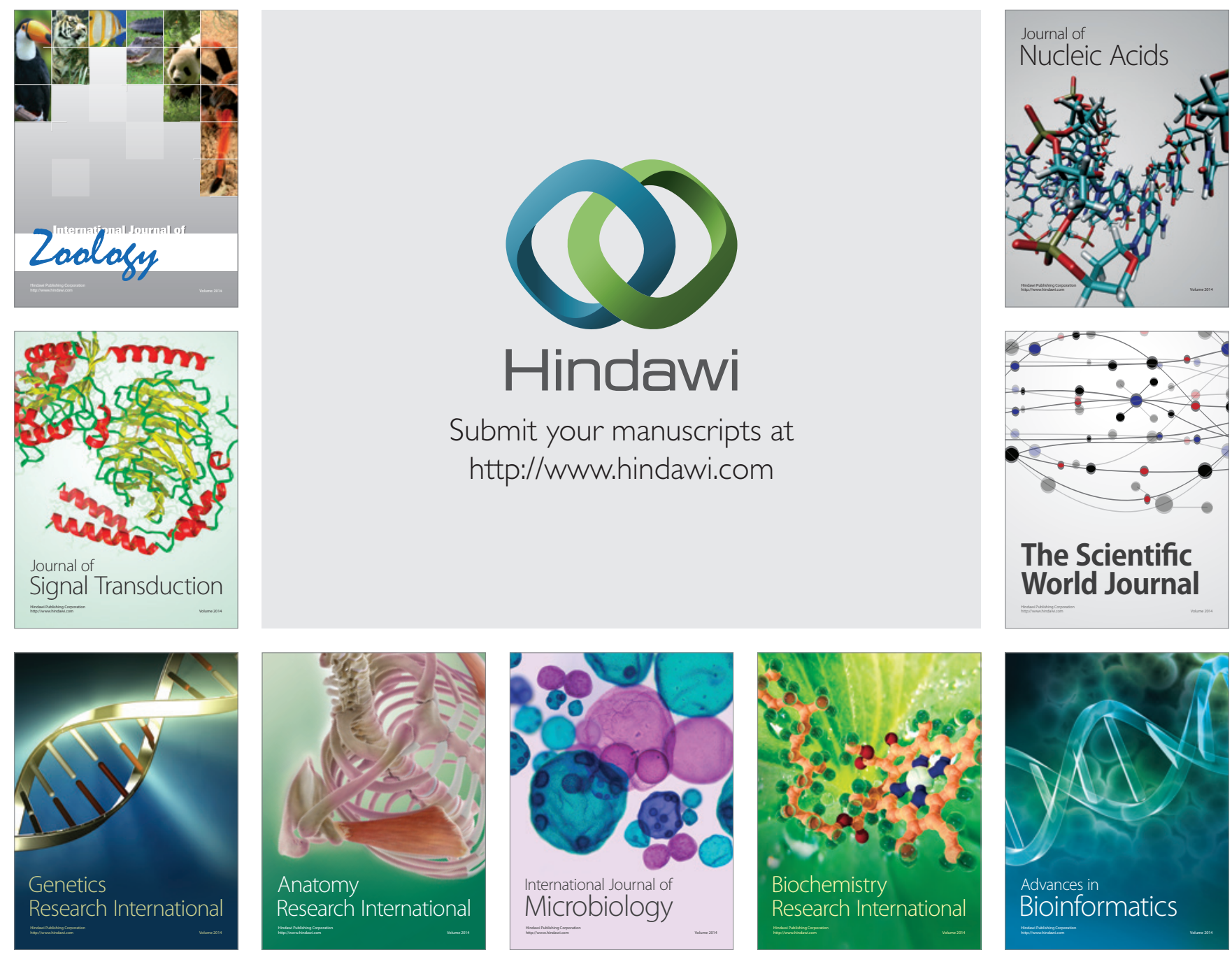

The Scientific World Journal
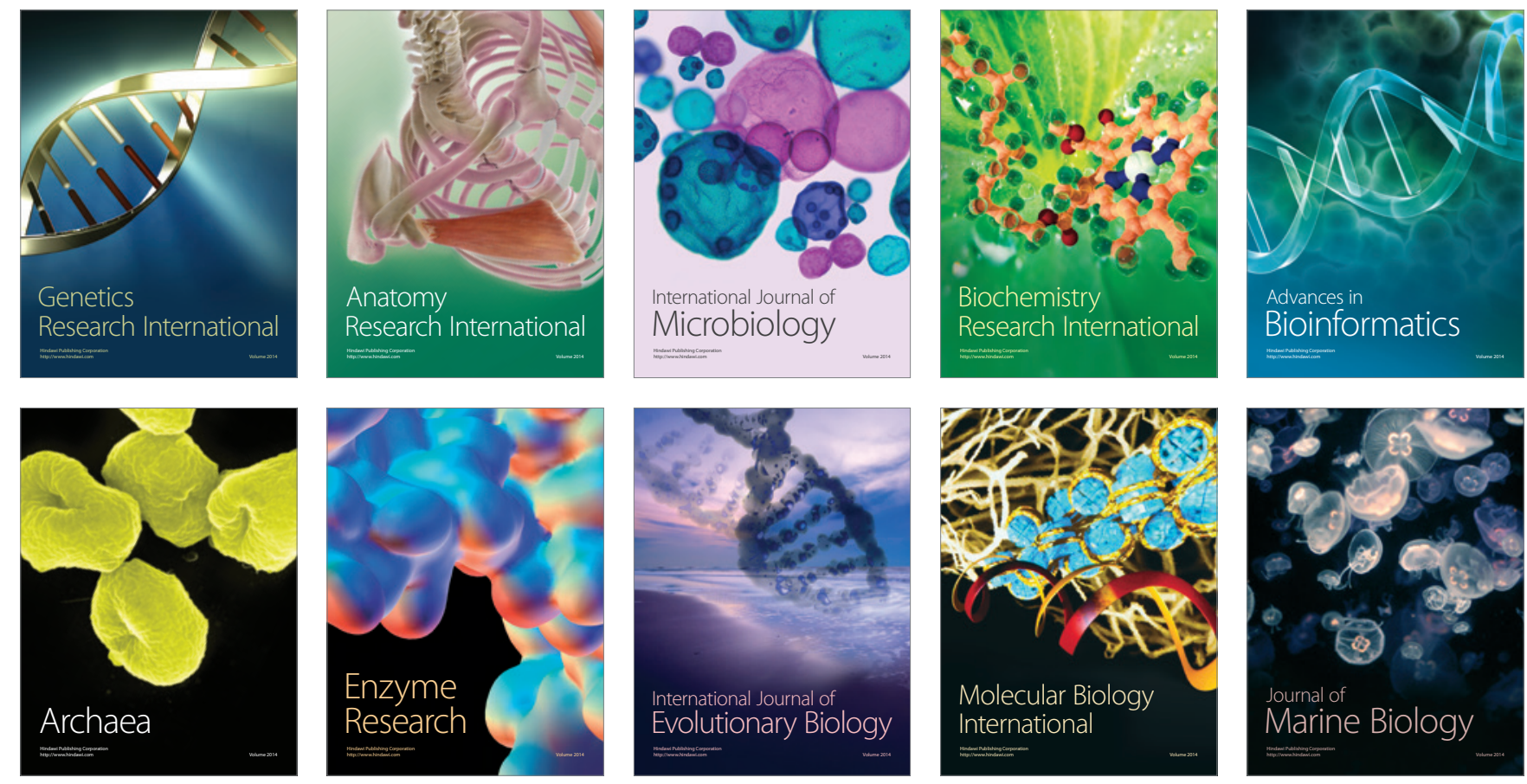